\title{
An efficient and economic enhancer mix for PCR is
}

\author{
Markus Ralser ${ }^{1}$, Robert Querfurth ${ }^{1}$, Hans-Jörg Warnatz, Hans Lehrach, \\ Marie-Laure Yaspo, Sylvia Krobitsch *
}

Max Planck Institute for Molecular Genetics, Ihnestrasse 73, 14195 Berlin, Germany

Received 19 June 2006

Available online 5 July 2006

\begin{abstract}
Polymerase chain reaction (PCR) has become a fundamental technique in molecular biology. Nonetheless, further improvements of the existing protocols are required to broaden the applicability of PCR for routine diagnostic purposes, to enhance the specificity and the yield of PCRs as well as to reduce the costs for high-throughput applications. One known problem typically reported in PCR experiments is the poor amplification of GC-rich DNA sequences. Here we designed and tested a novel effective and low-cost PCR enhancer, a concentration-dependent combination of betaine, dithiothreitol, and dimethyl sulfoxide that broadly enhanced the quantitative and/or qualitative output of PCRs. Additionally, we showed that the performances of this enhancer mix are comparable to those of commercially available PCR additives and highly effective with different DNA polymerases. Thus, we propose the routine application of this PCR enhancer mix for low- and high-throughput experiments.
\end{abstract}

(C) 2006 Elsevier Inc. All rights reserved.

Keywords: Polymerase chain reaction; GC-rich sequence; Enhancer; Additive; Promoter PCR; Genomic PCR; PCR template; Taq DNA polymerase

The polymerase chain reaction (PCR) was developed in the 1980s by Kary Mullis and Fred Faloona [1,2]. Starting with the biotechnological application of thermostable DNA polymerases [3], PCR has become a fundamental technique in molecular biology. There are ever-increasing needs for further improvements of PCR protocols for low-cost and efficient high-throughput approaches in a wide range of applications ranging from quantitative analysis at the genome- or transcriptome levels to routine diagnostic purposes [4,5]. Large-scale PCR experiments require broadly applicable and reliable reaction conditions for establishing cost-effective production pipelines. Taq DNA polymerase, originally purified from the thermophilic bac-

\footnotetext{
Abbreviations: BSA, bovine serum albumin; CES, combinatorial PCR enhancer solution; DMSO, dimethyl sulfoxide; DTT, dithiothreitol; PCR, polymerase chain reaction; Taq, Thermus aquaticus.

* Corresponding author.

E-mail addresses: ralser@molgen.mpg.de (M. Ralser), krobitsc@ molgen.mpg.de (S. Krobitsch).

${ }^{1}$ These authors contributed equally to this work.
}

terium Thermus aquaticus [6], is widely used, since it can be produced in every standard laboratory at low-cost [7-9]. One major factor limiting the output of PCR routines is that a number of DNA sequences are poorly or not amplifiable under standard reaction conditions, either because of their intrinsic properties to form secondary structures, and/ or because of their high GC-content. Improvements of the PCR conditions can be achieved by modifying the classical reaction conditions, for example, by performing "touchdown" PCR, consisting of a stepwise reduction of the annealing temperature for each cycle [10], or by the use of modified DNA polymerases for carrying out "hot-start" reactions [11]. Typically, to overcome amplification problems of GC-rich DNA, the addition of substances that enhance the specificity and/or the yield of the PCR is necessary. The most prominent PCR enhancing additives that are currently used are either betaine [12], small sulfoxides like dimethyl sulfoxide (DMSO, [13]), small amides like formamide [14] or reducing compounds like $\beta$-mercaptoethanol or dithiothreitol (DTT, [10]). However, their capacity to significantly improve PCR yields mainly for 
high-throughput experiments is marginal. Commercial enhancers have led to better results but with two major drawbacks, their cost and the fact that their chemical composition is unknown.

Mammalian promoter sequences often contain highly GC-rich regions, which are difficult to amplify under standard reaction conditions [15]. In this study, we tested the efficacy of concentration-dependent combinations of different PCR additives for a reliable amplification of genomic DNA corresponding to a set of human promoter sequences and generated a novel, cheap, and flexible PCR enhancer.

\section{Materials and methods}

Primer design. PCR primers for the amplification of $\sim 1000-1600 \mathrm{bp}$ sized DNA fragments from human genomic DNA were designed using the "Primer 3.0" online service [16] on the basis of the human genome annotation build 35.1 (NCBI). The primer sequences, locus information, the overall GC-content, and the size of the expected amplicons are given in the supplementary material Table 1.

Purification of human genomic DNA. Human genomic DNA was prepared from oral mucosa. The mucosal smear was washed with water and dissolved in $400 \mu \mathrm{l}$ lysis buffer ( $50 \mathrm{mM}$ Tris- $\mathrm{HCl}, 10 \mathrm{mM}$ EDTA, and $2 \%$ SDS, pH 8.8). The suspension was incubated for $5 \mathrm{~min}$ at $65^{\circ} \mathrm{C}$, then supplemented with $250 \mu \mathrm{l} 4.5 \mathrm{M} \mathrm{NaCl}$ and cleared by centrifugation. Genomic DNA was recovered from the supernatant by isopropanol precipitation.

PCR conditions. PCRs were performed in a $30 \mu \mathrm{l}$ volume in 96-well microtiter plates. Reaction buffer contained $65 \mathrm{mM}$ Tris- $\mathrm{HCl}, 16.6 \mathrm{mM}$ $\left(\mathrm{NH}_{4}\right)_{2} \mathrm{SO}_{4}, 3.1 \mathrm{mM} \mathrm{MgCl} 2$, and $0.01 \%$ (v/v) Tween $20, \mathrm{pH}$ 8.0. $2.5 \mathrm{U} \mathrm{Taq}$ DNA polymerase purified from Escherichia coli according to the method of Engelke et al. [7], $0.6 \mu \mathrm{mol}$ of each oligonucleotide, and $25 \mu \mathrm{mol} \mathrm{dATP}$, dTTP, dCTP, and dGTP were added prior to the cycling reaction. The cycling reactions were performed in a PTC-200 Thermocycler (MJ Research) with an initial denaturation for $5 \mathrm{~min}$ at $96{ }^{\circ} \mathrm{C}$ followed by the thermal cycles as follows: denaturation step at $98^{\circ} \mathrm{C}$ for $15 \mathrm{~s}$, annealing step at $72{ }^{\circ} \mathrm{C}$ for $40 \mathrm{~s}$, and an elongation step at $72{ }^{\circ} \mathrm{C}$ for $90 \mathrm{~s}$. The annealing step was started at a temperature of $66^{\circ} \mathrm{C}$ and declined in $0.5^{\circ} \mathrm{C}$ steps for each cycle until a temperature of $56^{\circ} \mathrm{C}$ was reached. Subsequently, 30 additional cycles were performed with a constant annealing temperature of $52^{\circ} \mathrm{C}$. The reaction was completed with a final elongation step at $72{ }^{\circ} \mathrm{C}$ for $2 \mathrm{~min}$. PCR products were analyzed with agarose-gel electrophoresis and stained with ethidium bromide (Sigma).

\section{Results and discussion}

In the context of a systematic project aiming at the functional analysis of promoter elements, we set out to amplify 110 human promoter sequences from genomic DNA using classic touch-down PCR conditions (as described in Materials and methods). We observed that approx. 30\% of the promoter regions could not be correctly amplified, either because the PCR products were unspecific or because of the poor yield of the amplicons. Most of these had an overall GC-content of 50-75\% (62\% in average).

In order to improve these results, we evaluated different PCR enhancing additives for their capacity to promote the amplification of three different gene promoter regions (SIM2, DIP2A, and SLC19A1, please refer to the supplementary material for detailed information) whose GC-content ranged from $71 \%$ to $75 \%$. We designed three primer pairs for these promoters (named A for SIM2, B for DIP2A, and C for SLC19A1) and carried out touch-down PCR supplemented with different concentration ranges of the PCR additives betaine [12], dithiothreitol (DTT) [10], dimethyl sulfoxide (DMSO) [13], or formamide [14] as indicated in Fig. 1. We observed that betaine had the best PCR enhancing properties at a concentration of $0.8 \mathrm{M}$ in all PCR samples for primer pairs A, B, and C, whereas DTT and DMSO were less effective since the PCR output was enhanced only for one gene out of three (3.2 mM DTT for primer pair A, or $3.2 \%$ DMSO for primer pair B, respectively) (Fig. 1). No PCR enhancing effects were observed by adding formamide to the respective PCRs at any of the indicated concentrations.

On this basis, we generated a 5-times concentrated preliminary combinatorial enhancer solution (preCES-I) composed of $4 \mathrm{M}$ betaine, $16 \mathrm{mM}$ DTT, and 16\% DMSO. We included $83 \mu \mathrm{g} / \mathrm{ml}$ bovine serum albumin (BSA) in the solution, since BSA, which has no direct effect on the enzymatic reaction per se, can stabilize enzymes and neutralize inhibitory contaminants that may be present in the DNA
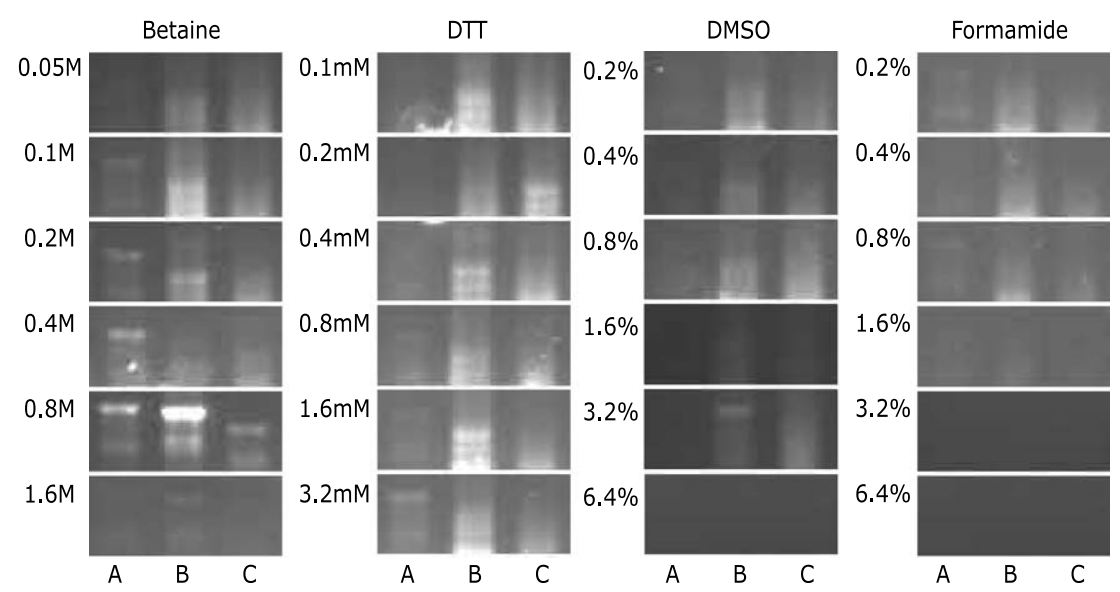

Fig. 1. Enhancing properties of known PCR additives. Betaine, DTT, DMSO, and formamide were applied to genomic PCRs at the indicated final concentrations. Letters represent the primer pairs used. 
template preparation or in the reaction buffers $[10,17]$. Since high compound concentration could potentially inhibit the activity of the Taq DNA polymerase, we additionally tested two other preCESs containing lower concentrations of the respective additives, preCES-II (4 M betaine, $10 \mathrm{mM}$ DTT, and 10\% DMSO) and preCES-III, ( $2 \mathrm{M}$ betaine, $5 \mathrm{mM}$ DTT, and 5\% DMSO). To analyze the efficiency of these preliminary enhancer solutions, we selected 12 ( 9 additional) primer pairs, of which 10 failed to produce adequate PCR products under standard conditions without additive. These primer pairs produced either non-specific products $(\mathrm{H}$ and $\mathrm{I})$, prominent additional bands to the expected product $(\mathrm{C}, \mathrm{D}$, and $\mathrm{L})$, very low yield (A, E, and K), or no product at all (B and G) (Fig. 2A). Subsequently, PCRs were repeated with these primers with or without preCESs I, II, or III. As demonstrated in Fig. 2A, the output of 10 out of 12 PCRs analyzed was enhanced by at least one of the three preCESs. For primer pairs $B$ and $G$, which have not resulted in any detectable PCR product, the addition of the preCESs resulted in the amplification of a specific DNA fragment. For primer pairs $\mathrm{C}, \mathrm{D}, \mathrm{H}, \mathrm{L}$, or I, respectively, the preCESs enhanced the specificity of the PCRs, whereas for primer pairs A, E, and $\mathrm{K}$ the presence of at least one preCES resulted in a significantly improved product yield. However, the addition of preCESs did not improve the PCR performed with primer pair $\mathrm{F}$, and in one case the addition of preCESs had a negative effect on the PCR yield (primer pair J).

Thus, these experiments clearly demonstrated that the addition of a preCES enhances the yield and/or the specificity of PCRs in virtually all cases, particularly for the amplification of highly GC-rich sequences up to $75 \%$. Among the three tested enhancers, preCES-II containing the intermediate concentrated enhancer solution appeared to perform best, as visualized in Fig. 2B.

In the next step, we further optimized further the compound concentration of the preCES-II. Initially, the $30 \mu \mathrm{l}$ PCR mixture was supplemented with incremental quantities of preCES-II in $2 \mu \mathrm{l}$ steps (ranging from $0 \%$ to $40 \%$ of the final volume) and PCRs were performed with the various primer pairs as indicated (Fig. 2C). Best results in terms of specificity and yield were obtained with addition of $4 \mu \mathrm{l}$ preCES-II to the $30 \mu \mathrm{l}$ reaction volume, corresponding to final concentrations of $0.54 \mathrm{M}$ betaine, $1.34 \mathrm{mM}$ DTT, $1.34 \% \mathrm{DMSO}$, and $11 \mu \mathrm{g} / \mathrm{ml}$ BSA. Thus, we generated a 5-times concentrated combinatorial enhancer solution termed CES.

In a third step, we compared the efficiency of our CES with those of three commercial PCR enhancer solutions, namely Q-solution (Qiagen), PCR enhancer solution (Invitrogen), and Hi-Spec PCR additive (Bioline). For this comparative analysis, we selected 32 primer pairs designed for the amplification of DNA fragments with a GC-content ranging from $33 \%$ to $75 \%$ (Fig. 3A). PCRs were performed using the reaction buffer without additives or supplemented with the Q-solution, PCR enhancer solution, Hi-Spec PCR additive or our CES. As demonstrated in Fig. 3A, commercial PCR enhancers could improve $90 \%$ of the PCRs. The CES described in this study led to comparable performances in all tested PCRs. A major advantage of the CES is that it is much more economic for laboratory routine applications and that its composition is well described and can thus be tuned whenever necessary for more specific applications. Furthermore, Qiagen's Q-solution and Invitrogen's PCR enhancer mix can only be purchased conjoint with the suppliers Taq
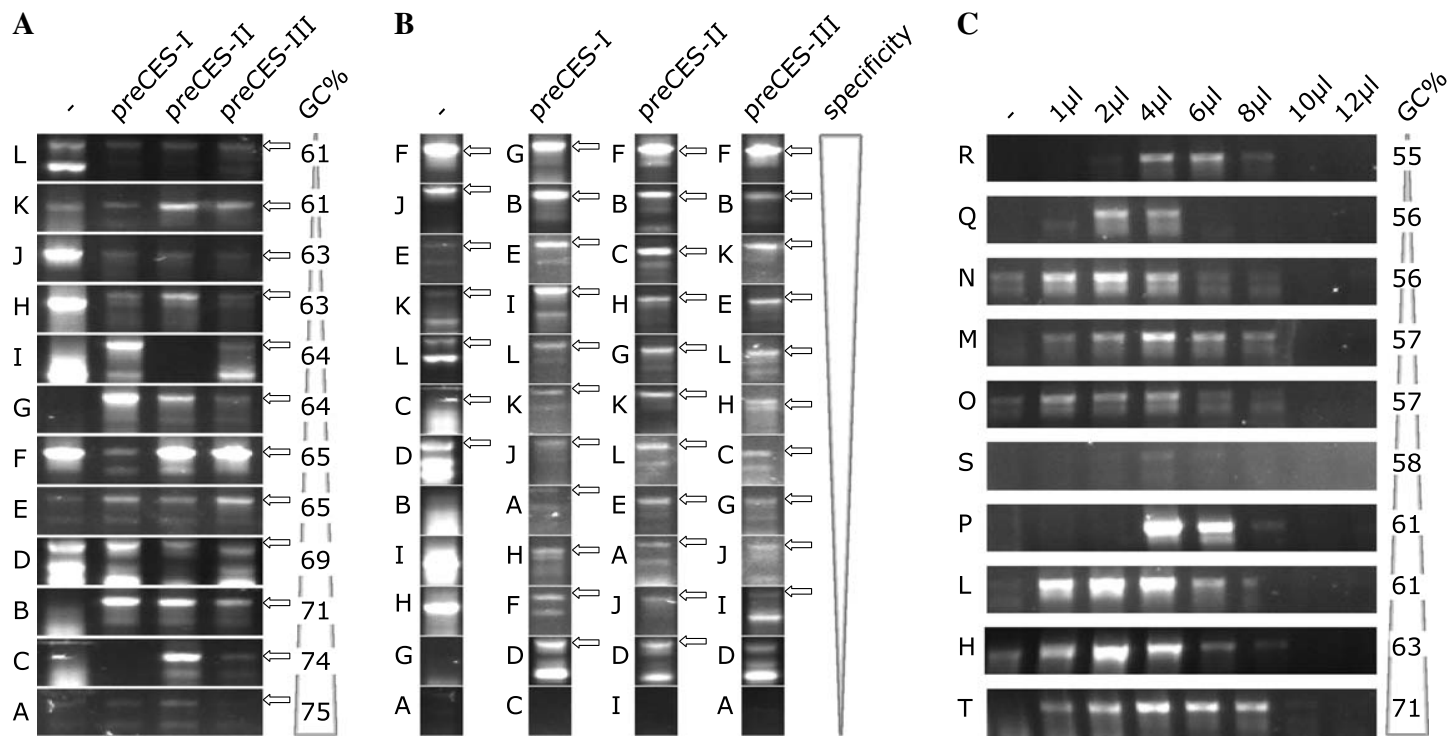

Fig. 2. Generation of a combinatorial enhancer solution (CES). (A) Comparative analysis of PCRs without enhancing additives (-) and PCRs supplied with preCES-I, preCES-II, or preCES-III, respectively. Primer pairs are sorted by ascending GC-content of the expected PCR product. Arrows highlight the specific DNA fragments. (B) Like (A), but sorted by descending product specificity and yield. (C) Concentration-dependent application of preCES-II to PCRs performed with primer pairs for the amplification of DNA sequences with varying GC-content. 

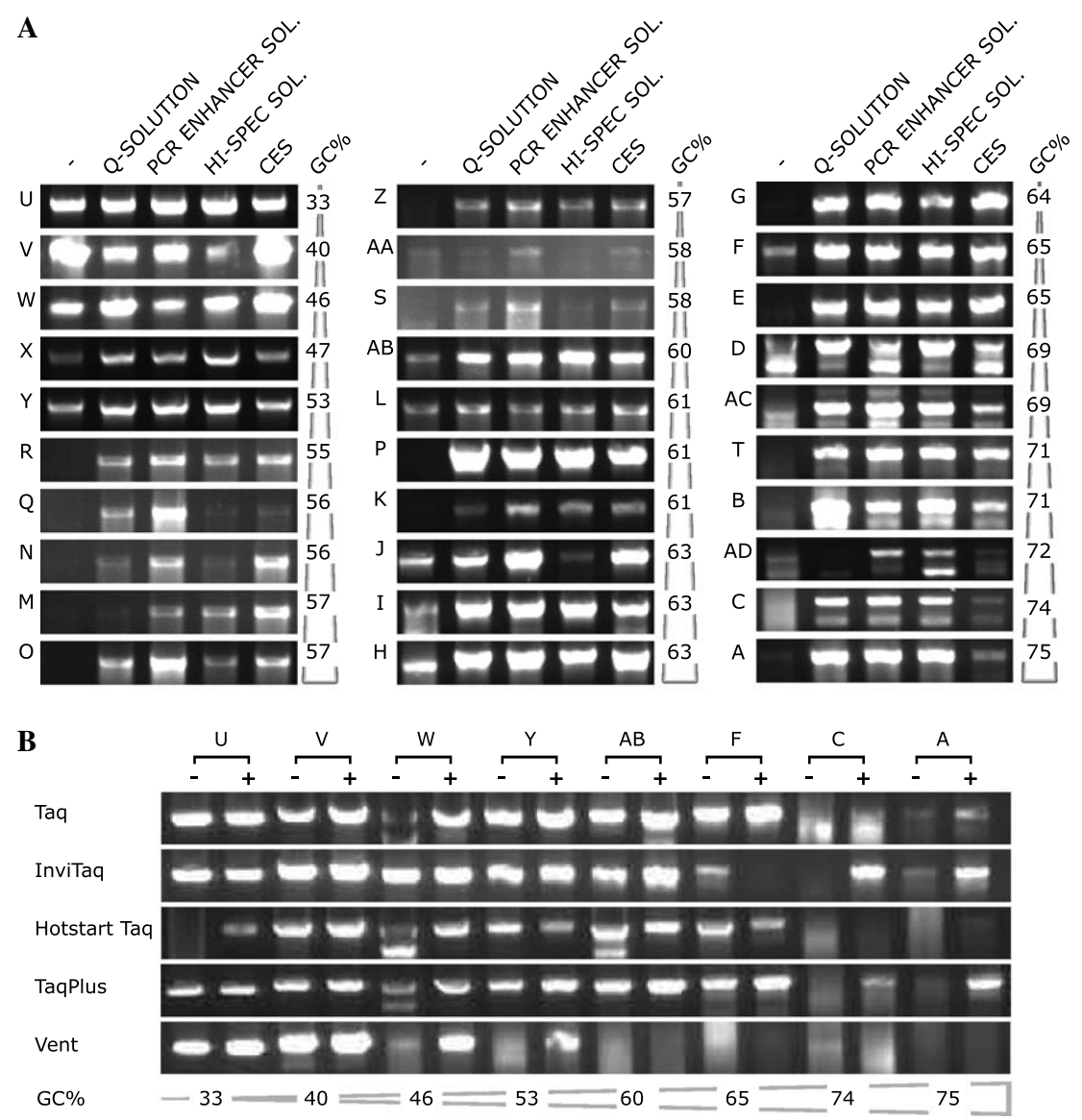

Fig. 3. Validation of the CES. (A) Comparison of PCRs without enhancing additives and PCRs supplied with Q-solution (Qiagen), PCR enhancer solution (Invitrogen), Hi-Spec PCR additive (Bioline), and the elaborated CES. Primer pairs are sorted by ascending GC-content of the expected DNA product. (B) Analysis of CES in combination with commercial DNA polymerases. PCRs were performed with $(+)$ or without $(-)$ CES using the commercial DNA polymerases as indicated.

polymerase (Qiagen) or with a proprietary reaction buffer (Invitrogen). To exclude that the PCR enhancing effects of CES are limited to PCRs performed with our homemade Taq DNA polymerase, we further analyzed the performance of CES with commercial polymerases. Using DNA polymerases like InviTaq (Invitek), HotStartTaq (Qiagen), TaqPlus (Stratagene) or even with Vent polymerase, originally purified from Thermococcus litoralis ([18], New England BioLabs), we amplified eight different genomic DNA fragments with or without CES (Fig. 3B). The majority of PCRs with inadequate products were enhanced and virtually no negative effects resulting from the addition of the CES were observed in all reactions. Thus, our enhancer solution can be used with any of the tested DNA polymerases. Interestingly, the extremely GC-rich DNA fragments resulting from primer pair A or C (75\% and $74 \%$, respectively) that were poorly amplified with the home-made Taq DNA polymerase even in the presence of CES were satisfactorily amplified using CES in combination with the InviTaq or TaqPlus enzyme, respectively (Fig. 3A and B). Finally, to support the broad applicability of this PCR enhancer, we also tested the CES on other types of template DNA like yeast genomic DNA, plasmids, and even glycerol stocks, and detect- ed PCR enhancing effects of the CES (data not shown). The 5-times concentrated CES containing $2.7 \mathrm{M}$ betaine, $6.7 \mathrm{mM}$ DTT, $6.7 \%$ DMSO, and $55 \mu \mathrm{g} / \mathrm{ml}$ BSA was stable at $-20^{\circ} \mathrm{C}$ for at least 3 months. Since different Taq reaction buffers currently in use show diverse performances, we recommend to use a reaction buffer containing final concentrations of $65 \mathrm{mM}$ Tris-Cl, $16.6 \mathrm{mM}\left(\mathrm{NH}_{4}\right)_{2} \mathrm{SO}_{4}$, $3.1 \mathrm{mM} \mathrm{MgCl} 2$, and $0.01 \%$ (v/v) Tween 20 at a pH of 8.8 as described in the Materials and methods section.

In summary, we have demonstrated that the concentration-dependent combination of the known PCR additives betaine, DMSO, and DTT results in a cost-effective PCR enhancer solution showing equivalent performances compared with commercial enhancers, at least under the chosen experimental conditions. Since the CES is composed of low-cost components, the usage of this PCR enhancer solution is especially advantageous and attractive from the economic perspective for large-scale projects and routine applications requiring reliable PCR results.

\section{Acknowledgments}

We are grateful to Richard Reinhardt and Roman Pawlik (Max Planck Institute for Molecular Genetics, Berlin, 
Germany) for providing Taq DNA polymerase and to our lab members for critical discussions. This work has been funded by the Max Planck Society and the Federal Ministry of Education and Research (BMBF) in the framework of the National Genome Research Network (NGFN) under project $01 \mathrm{GR} 0414$.

\section{Appendix A. Supplementary data}

Supplementary data associated with this article can be found, in the online version, at doi:10.1016/ j.bbrc.2006.06.151.

\section{References}

[1] K.B. Mullis, The unusual origin of the polymerase chain reaction, Sci. Am. 262 (1990) 56-61, 64-65.

[2] R.K. Saiki, S. Scharf, F. Faloona, K.B. Mullis, G.T. Horn, H.A. Erlich, N. Arnheim, Enzymatic amplification of beta-globin genomic sequences and restriction site analysis for diagnosis of sickle cell anemia, Science 230 (1985) 1350-1354.

[3] R.K. Saiki, D.H. Gelfand, S. Stoffel, S.J. Scharf, R. Higuchi, G.T. Horn, K.B. Mullis, H.A. Erlich, Primer-directed enzymatic amplification of DNA with a thermostable DNA polymerase, Science 239 (1988) 487-491.

[4] G. Csako, Present and future of rapid and/or high-throughput methods for nucleic acid testing, Clin. Chim. Acta 363 (2006) 6-31.

[5] C. Ding, C.R. Cantor, Quantitative analysis of nucleic acids-the last few years of progress, J. Biochem. Mol. Biol. 37 (2004) 1-10.

[6] F.C. Lawyer, S. Stoffel, R.K. Saiki, S.Y. Chang, P.A. Landre, R.D. Abramson, D.H. Gelfand, High-level expression, purification, and enzymatic characterization of full-length Thermus aquaticus DNA polymerase and a truncated form deficient in $5^{\prime}$ to $3^{\prime}$ exonuclease activity, PCR Methods Appl. 2 (1993) 275-287.
[7] D.R. Engelke, A. Krikos, M.E. Bruck, D. Ginsburg, Purification of Thermus aquaticus DNA polymerase expressed in Escherichia coli, Anal. Biochem. 191 (1990) 396-400.

[8] F.C. Lawyer, S. Stoffel, R.K. Saiki, K. Myambo, R. Drummond, D.H. Gelfand, Isolation, characterization, and expression in Escherichia coli of the DNA polymerase gene from Thermus aquaticus, J. Biol. Chem. 264 (1989) 6427-6437.

[9] F.G. Pluthero, Rapid purification of high-activity Taq DNA polymerase, Nucleic Acids Res. 21 (1993) 4850-4851.

[10] M. Nagai, A. Yoshida, N. Sato, Additive effects of bovine serum albumin, dithiothreitol, and glycerol on PCR, Biochem. Mol. Biol. Int. 44 (1998) 157-163.

[11] D.E. Kellogg, I. Rybalkin, S. Chen, N. Mukhamedova, T. Vlasik, P.D. Siebert, A. Chenchik, TaqStart Antibody: "hot start" PCR facilitated by a neutralizing monoclonal antibody directed against Taq DNA polymerase, Biotechniques 16 (1994) 1134-1137.

[12] W. Henke, K. Herdel, K. Jung, D. Schnorr, S.A. Loening, Betaine improves the PCR amplification of GC-rich DNA sequences, Nucleic Acids Res. 25 (1997) 3957-3958.

[13] R. Chakrabarti, C.E. Schutt, The enhancement of PCR amplification by low molecular-weight sulfones, Gene 274 (2001) 293-298.

[14] G. Sarkar, S. Kapelner, S.S. Sommer, Formamide can dramatically improve the specificity of PCR, Nucleic Acids Res. 18 (1990) 7465.

[15] F. Hube, P. Reverdiau, S. Iochmann, Y. Gruel, Improved PCR method for amplification of GC-rich DNA sequences, Mol. Biotechnol. 31 (2005) 81-84.

[16] S. Rozen, H. Skaletsky, Primer3 on the WWW for general users and for biologist programmers, Methods Mol. Biol. 132 (2000) $365-386$.

[17] T. Maniatis, E.F. Fritsch, J. Sambrook, Molecular cloning : a laboratory manual, 2nd ed., Cold Spring Harbor Laboratory, Cold Spring Harbor, NY, 1987.

[18] F.B. Perler, D.G. Comb, W.E. Jack, L.S. Moran, B. Qiang, R.B. Kucera, J. Benner, B.E. Slatko, D.O. Nwankwo, S.K. Hempstead, et al., Intervening sequences in an Archaea DNA polymerase gene, Proc. Natl. Acad. Sci. USA 89 (1992) 5577-5581. 